Case Report

\title{
Granuloma Annulare, Autoimmune Thyroiditis, and Lichen Sclerosus in a Woman: Randomness or Significant Association?
}

\author{
Mariele De Paola, Anastasia Batsikosta, Luca Feci, Mattia Benedetti, and Roberta Bilenchi \\ Department of Clinical Medicine and Immunological Sciences, Section of Dermatology, University of Siena, \\ Policlinico "Le Scotte", 53100 Siena, Italy \\ Correspondence should be addressed to Mariele De paola; marieledepaola@libero.it
}

Received 22 February 2013; Accepted 27 March 2013

Academic Editors: S. A. Cuevas-Covarrubias, K. Jimbow, M. Jinnin, R. Krishnan, and G. E. Piérard

Copyright (C) 2013 Mariele De Paola et al. This is an open access article distributed under the Creative Commons Attribution License, which permits unrestricted use, distribution, and reproduction in any medium, provided the original work is properly cited.

We report a 60-year-old Caucasian female with a 2-year history of diffused granuloma annulare (GA), who presented for the simultaneous occurrence of genital lichen sclerosus (LS) and autoimmune thyroiditis (AT). In our opinion this combination is not just coincidental but may share similar immunopathological mechanisms.

\section{Introduction}

GA is one of the "ten noninfectious granulomatous diseases" of the skin, a broad group of distinct reactive inflammatory conditions that share important similarities and that have significant associations with systemic diseases [1]. GA is a benign self-limiting, relatively common dermatosis, typically characterized by an annular arrangement of erythematous or flesh-coloured papules, affecting patients of all ages. Incidence is highest in women, with a ratio of 2.3 to 1.0 over men [2]. The cause of GA is still unknown, but it has been reported following traumas, malignancy, viral infections (including human immunodeficiency virus HIV, EpsteinBarr virus (EBV), and herpes zoster ( $\mathrm{HZV})$ ), insect bites, and tuberculosis skin tests [3]. The pathogenesis of GA remains still obscure. Possible pathogenetic factors suggested include humoral and delayed type hypersensitivity, vascular damage, metabolic disorder, or primary collagen and/or elastin alteration mediated through an immunologic mechanism [3].

LS is a chronic inflammatory mucocutaneous disease, commonly associated with HLA type B40 related to high incidence of autoimmune diseases, that mainly affects women in the 5th decade but may occur in all age groups, including adolescents and prepubertal children. Its exact prevalence is unknown, but estimates range from $1: 60$ to $1: 1000$. [4]. The etiology is still obscure, although genetic and autoimmune factors, as well as infections, have been implicated in its pathogenesis. It is most commonly seen on the female genital skin, but it also occurs on extragenital areas. Most patients complain of itching and, less frequently, burning sensation, dyspareunia, dysuria, and painful defecation [5].

Autoimmune thyroid disease (AITD) is the most common organ-specific autoimmune disorder, usually resulting in dysfunction (hyperfunction, hypofunction, or both) of the thyroid gland. In some patients, other organ-specific and non-organ-specific autoimmune syndromes are associated with autoimmune thyroid disease, including pernicious anemia, vitiligo, myasthenia gravis, primary adrenal autoimmune disease, celiac disease, rheumatoid arthritis, or lupus [6]. We report a case of GA, AT, and LS in a woman and discuss their comorbidity.

\section{Case Presentation}

A 60-year-old Caucasian female presented with a history of 2-year annular arrangement of erythematous papules at the right arm and hands (Figure 1), histologically confirmed as GA (Figure 2). The patient was treated topically with clobetasol propionate ointment and pimecrolimus cream for three months with partial resolution. Two years after, the patient developed vulvar LS (Figures 3 and 4). On admission, routine hematologic and chemistry analyses were in the normal range with the exception of positive speckled pattern 


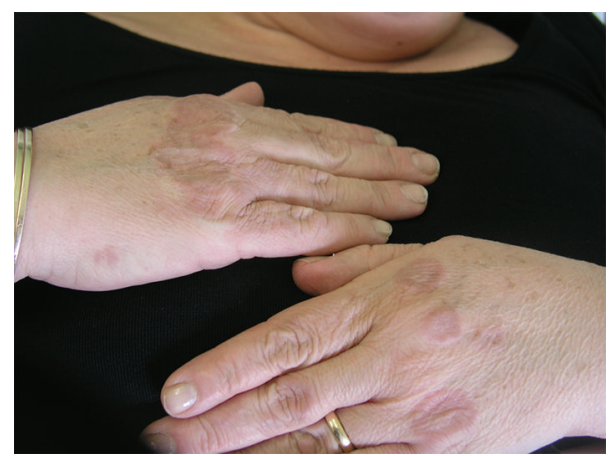

FIGURE 1: Woman with annular arrangement of erythematous and flesh-coloured papules at her hands.

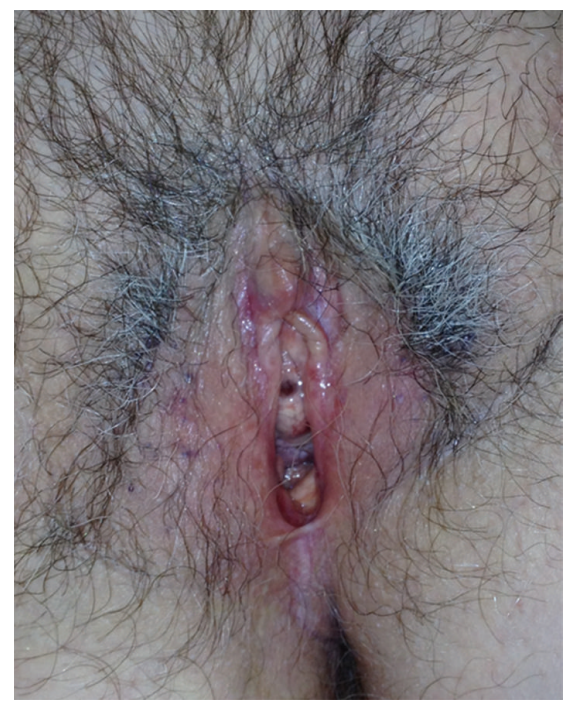

FIGURE 2: Lichen sclerosus with porcelain-white atrophic scarring, erosions, and hemorrhages in the genital area.

(1:160 titer) antinuclear antibody (ANA). Detection of serum antibodies to $B$. burgdorferi was negative. Thyroid function tests showed subclinical autoimmune hypothyroidism with elevated thyroid-stimulating hormone (TSH) values (7.7 UL/mL showed subclinical autoimmune hypothyroidism $421 \mathrm{IU} / \mathrm{ml}$; antimicrosomal of $43 \mathrm{IU} / \mathrm{mL}$ ). Thyroid ultrasound revealed multiple thyroid nodules. The patient was managed with methylprednisolone $4 \mathrm{mg}$ per day. After 2 months there was a favorable improvement of skin symptoms with incomplete clearing of lesions.

\section{Discussion}

GA associated with LS and autoimmune thyroiditis have been never reported to occur simultaneously while evidence of improvement to treatment with systemic steroids of a single disease is often reported. Some studies have indicated an association of skin granulomatous disease like granuloma annulare and autoimmune diseases like diabetes mellitus or Sjögren's syndrome or thyroid diseases. Some other studies have reported cooccurrence of LS with autoimmune diseases

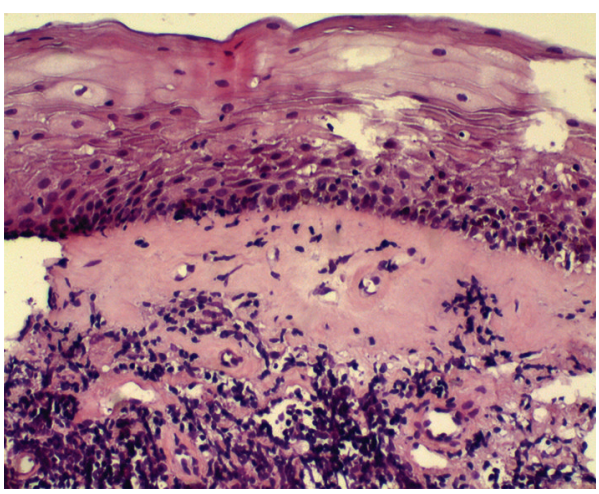

FIGURE 3: Epidermal thinning, dermic broad bundles of hyalinized collagen, and band-like lymphocytic infiltrate (haematoxylin eosin).

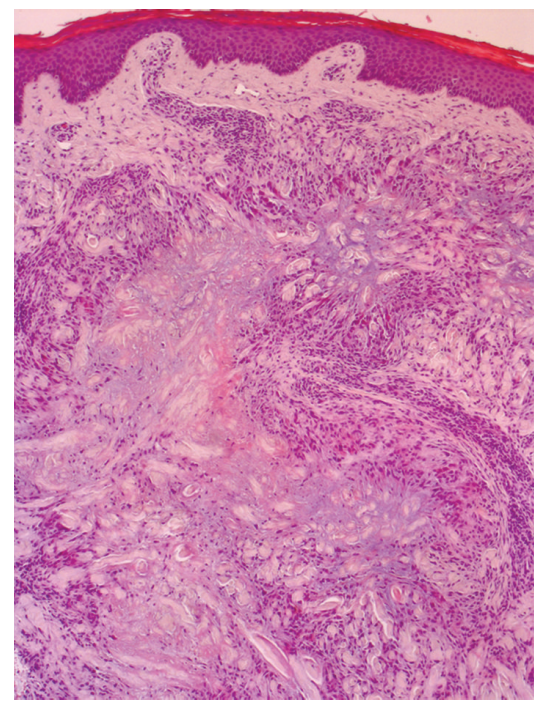

FIGURE 4: Normal epidermis. Palisaded granulomas of dermis with epithelioid histiocytes around a central zone of mucin (haematoxylin eosin).

including vitiligo, Hashimoto's thyroiditis and type 1 diabetes [7]. In the literature, it has been raised that this association is more than coincidence, and it suggests an autoimmune basis for these conditions (Table 1).

Granuloma annulare is a benign disease of unknown etiology with a lymphocyte-mediated hypersensitivity type IV mechanism where an immunologic cell-mediated process or a primary collagen and/or elastin destruction have often been suggested [8]. Lichen sclerosus is a chronic lymphocytemediated inflammatory skin disease, for which increasing evidence suggests an underlying autoimmune mechanism mainly in female genetically predisposed patients with HLADQ7 antigen; in fact antibodies against the basement membrane zone, chiefly Binding Protein (BP)180 and BP 230, have been found in $30 \%$ of sera of patients with LS, and a high proportion of patients (up to $80 \%$ ) have specific antibodies targeting extracellular matrix protein-1 [9]. On these basis we think, according to the literature, that the origin is most 
TABLE 1: Granulomatous diseases and autoimmune diseases associations.

\begin{tabular}{|c|c|c|}
\hline Author/year & Type of study & Associated disease/s \\
\hline Studer et al./1996 [10] & Retrospective study & Diabetes mellitus $10 / 84$ cases \\
\hline Erkek et al./2001 [11] & Case report & Insulin-dependent diabetes mellitus \\
\hline Vázquez-López et al./2003 [12] & Case-control study & Autoimmune thyroditis $3 / 24$ \\
\hline Tallab/2004 [13] & Case report & Autoimmune thyroditis \\
\hline Goucha et al./2008 [14] & Retrospective study (GA) & $\begin{array}{l}\text { Diabetes mellitus } 9 / 35 \text { cases } \\
\text { Thyroiditis } 2 / 35 \text { cases }\end{array}$ \\
\hline Davison et al./2010 [15] & Pediatric case report & $2 / 2$ cases of juvenile insulin-dependent diabete mellitus \\
\hline Sumikawa et al./2010 [16] & Case report & 1 case of Sjögren's syndrome \\
\hline Sehgal et al./2011 [17] & Review of clinical case histories (GA) & $\begin{array}{c}100 \text { patients with generalized granuloma annulare; } 13 \\
\text { patients were found to have thyroid disease, while } \\
\text { diabetes was diagnosed in } 21 \text { patients. }\end{array}$ \\
\hline
\end{tabular}

likely immunologic associated with a mechanism of inheritance. Interestingly, there is also evidence linking GA and autoimmune thyroiditis/insulin-dependent diabetes mellitus (IDDM), and evidence linking LS and AT that come from both limited epidemiologic data and clinical observations.

Actually, there is no definitive hypothesis that could explain the coexistence of GA, LS, and AT. However, we believe that in our patient, GA, with lymphocyte-mediated hypersensitivity type IV mechanism and a cell-mediated immune process, could contribute to trigger an organ-specific autoimmune response also in the genital mucosa or gland tissue, leading to the development of LP lesions and autoimmune thyroiditis. Further study is necessary to determine whether the LS, AT, and GA in our patient were an isolated coincidence or there is a causative link between those. We speculate that the pathogenesis of GA might play an important role in the genesis of the other diseases in this case.

Our case suggests that AT, GA, and LS may be closely related and that GA and LS should be recognized as two cutaneous manifestations associated with autoimmune diseases. However, we cannot exclude that comorbidity is exclusively a coincidence and further investigations are needed to better understand etiopathogenesis and develop more specific therapy.

\section{Conflict of Interests}

The authors declare that they have no conflict of interests.

\section{References}

[1] E. B. Hawryluk, L. Izikson, and J. C. English 3rd, "Noninfectious granulomatous diseases of the skin and their associated systemic diseases: an evidence-based update to important clinical questions," The American Journal of Clinical Dermatology, vol. 11, no. 3, pp. 171-181, 2010.

[2] M. V. Dahl, "Dahl MVGranuloma annulare," in Dermatology in General Medicine, T. B. Fitzpatrick, A. Z. Eisen, K. Wolff, I. M. Freedberg, and K. F. Austin, Eds., pp. 980-984, McGraw-Hill, New York, NY, USA, 6th edition, 2003.
[3] L. R. Stewart, S. George, K. L. Hamacher, and S. Hsu, "Granuloma annulare of the palms," Dermatology Online Journal, vol. 17 , no. 5, article 7, 2011.

[4] R. Murphy, "Lichen sclerosus," Dermatologic Clinics, vol. 28, no. 4, pp. 707-715, 2010.

[5] S. K. Fistarol and P. H. Itin, "Diagnosis and treatment of lichen sclerosus : an update," The American Journal of Clinical Dermatology, vol. 14, no. 1, pp. 27-47, 2013.

[6] B. Trbojević and S. Djurica, "Diagnosis of autoimmune thyroid disease," Srpski arhiv za celokupno lekarstvo, vol. 133, Supplement 1, pp. 25-33, 2005.

[7] J. J. Meffert, B. M. Davis, and R. E. Grimwood, "Lichen sclerosus," Journal of the American Academy of Dermatology, vol. 32, no. 3, pp. 393-416, 1995.

[8] P. J. Sniezek, J. R. Debloom, and C. J. Arpey, "Treatment of granuloma annulare with the $585 \mathrm{~nm}$ pulsed dye," Dermatologic Surgery, vol. 31, no. 10, pp. 1370-1373, 2005.

[9] A. Howard, D. Dean, S. Cooper, G. Kirtshig, and F. Wojnarows$\mathrm{ka}$, "Circulating basement membrane zone antibodies are found in lichen sclerosus of the vulva," The Australasian Journal of Dermatology, vol. 45, no. 1, pp. 12-15, 2004.

[10] E. M. Studer, A. M. Calza, and J. H. Saurat, "Precipitating factors and associated diseases in 84 patients with granuloma annulare: a retrospective study," Dermatology, vol. 193, no. 4, pp. 364-368, 1996.

[11] E. Erkek, A. Karaduman, G. Bükülmez, N. Sentürk, and O. Ozkaya, "An unusual form of generalized granuloma annulare in a patient with insulin-dependent diabetes mellitus," Acta Dermato-Venereologica, vol. 81, no. 1, pp. 48-50, 2001.

[12] F. Vazquez-Lopez, M. Pereiro Jr., J. A. M. Haces et al., "Localized granuloma annulare and autoimmune thyroiditis in adult women: a case-control study," Journal of the American Academy of Dermatology, vol. 48, no. 4, pp. 517-520, 2003.

[13] T. M. Tallab, "Localized granuloma annulare and autoimmune thyroiditis in a Saudi patient: report of a new case," West African Journal of Medicine, vol. 23, no. 3, pp. 264-266, 2004.

[14] S. Goucha, A. Khaled, M. Kharfi et al., "Granuloma annulare," $G$ Giornale Italiano di Dermatologia e venereologia : organo ufficiale, Società Italiana di Dermatologia e Sifilografia, vol. 143, no. 6, pp. 359-363, 2008.

[15] J. E. Davison, A. Davies, C. Moss, J. M. Kirk, S. M. Taibjee, and J. C. Agwu, "Links between granuloma annulare, necrobiosis 
lipoidica diabeticorum and childhood diabetes: a matter of time?" Pediatric Dermatology, vol. 27, no. 2, pp. 178-181, 2010.

[16] Y. Sumikawa, S. Ansai, T. Kimura, J. Nakamura, S. Inui, and I. Katayama, "Interstitial type granuloma annulare associated with Sjögren's syndrome," The Journal of Dermatology, vol. 37, no. 5, pp. 493-495, 2010.

[17] V. N. Sehgal, S. N. Bhattacharya, and P. Verma, "Juvenile, insulin-dependent diabetes mellitus, type 1-related dermatoses," Journal of the European Academy of Dermatology and Venereology, vol. 25, no. 6, pp. 625-636, 2011. 


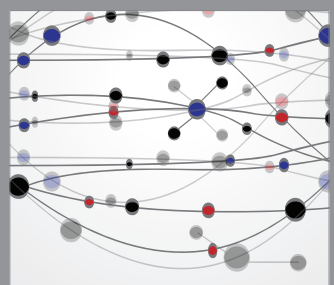

The Scientific World Journal
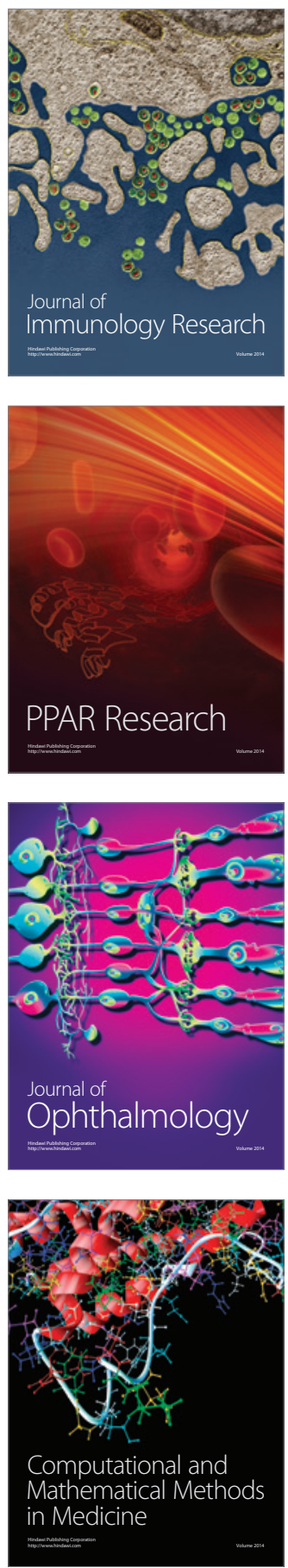

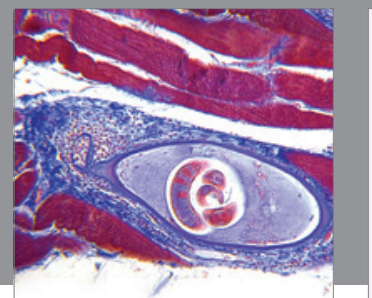

Gastroenterology

Research and Practice
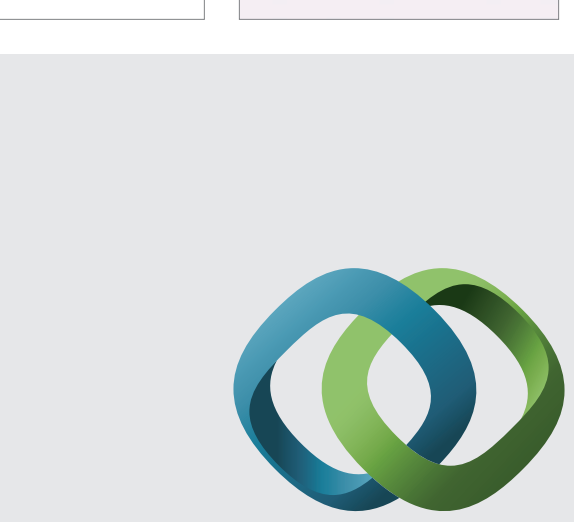

\section{Hindawi}

Submit your manuscripts at

http://www.hindawi.com
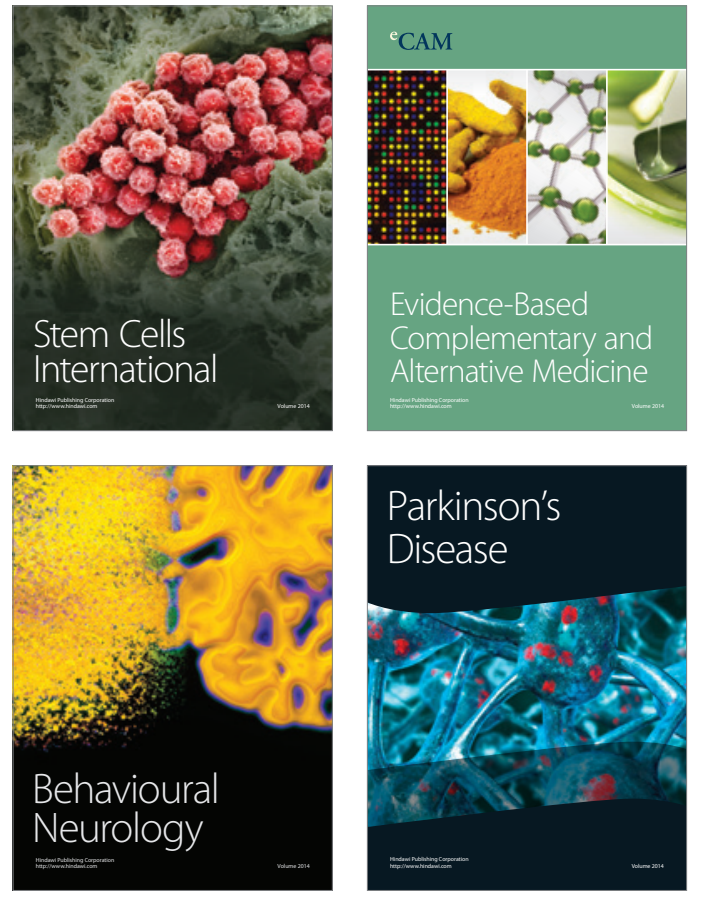
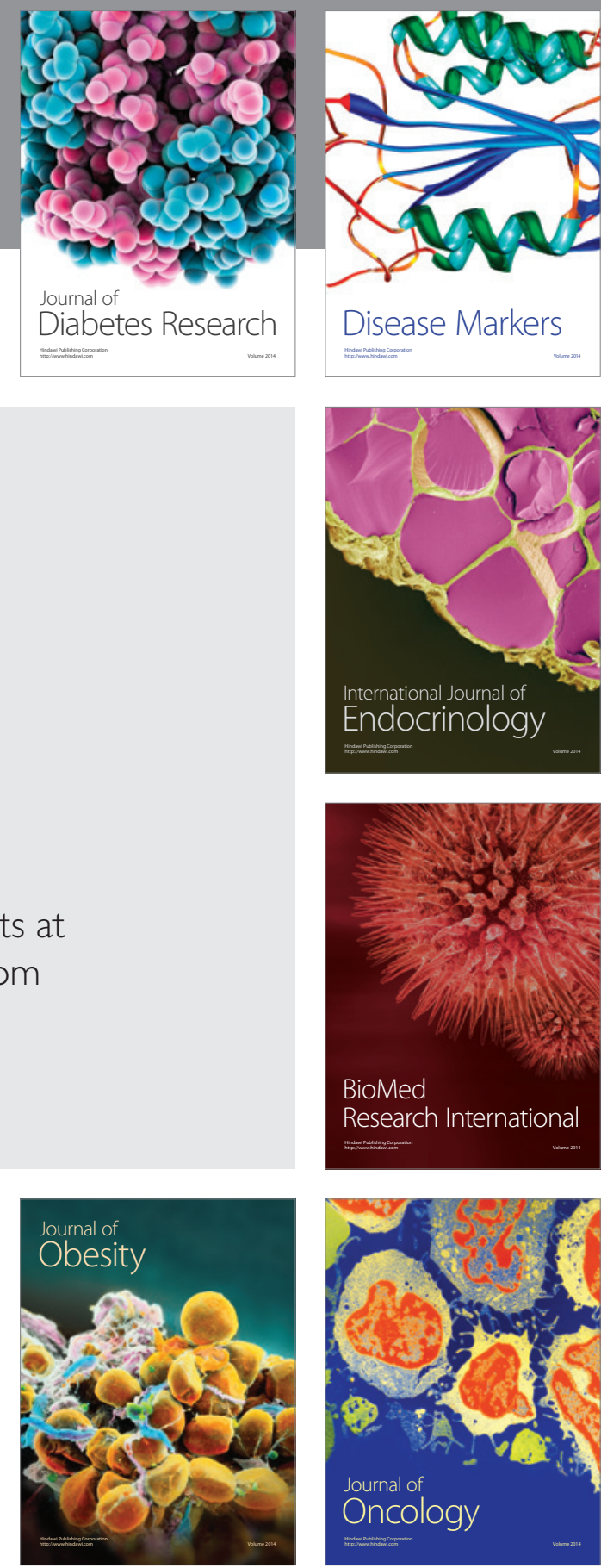

Disease Markers
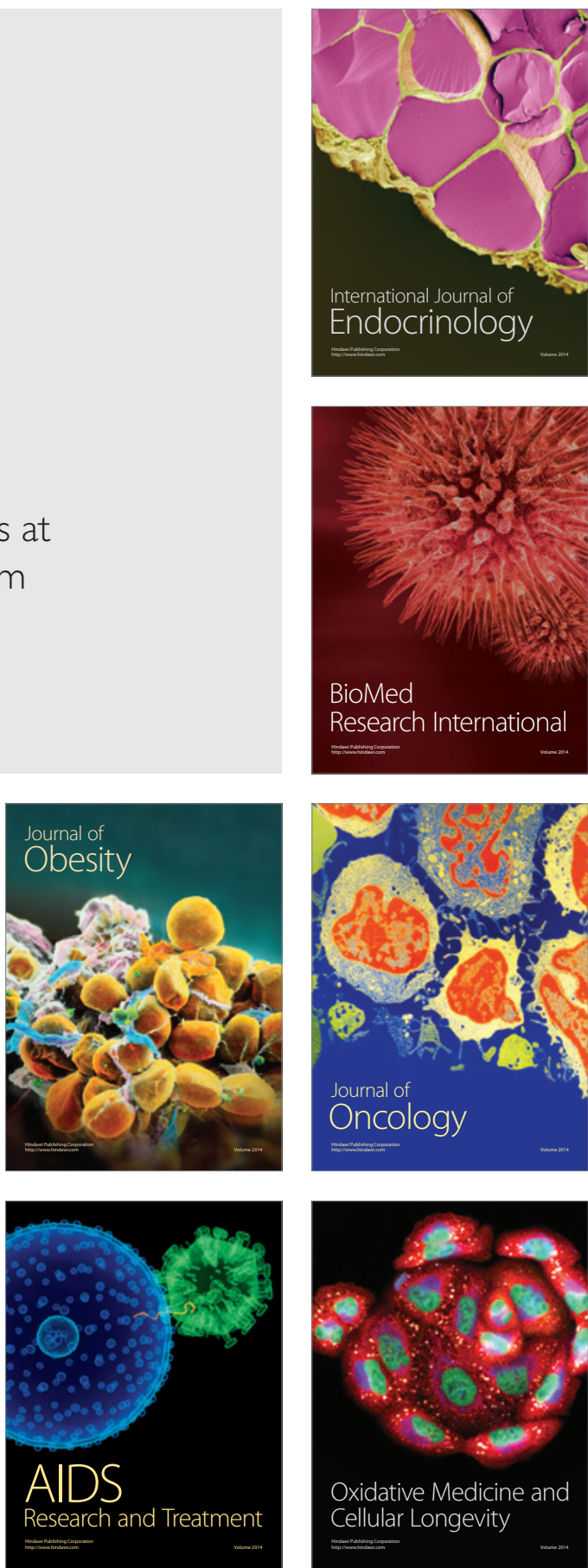